\title{
99\% Population Crash in Grass Moths (Crambus sp.) at The Pas, Manitoba.
}

WALTER KRIVDA, Box 864, The Pas, MB. R9A 1K8

Anyone who mows grass knows the small white moths that fly 2 meters ahead of the mower. They rise and settle again, and some years they occur in swarms. They were absent this year. This was the first year in my memory that all Crambus had completely vanished - none flew ahead of the mower. I watched particularly if a later flight occurred - none did. There are several species that fly together over our lawns. Apparently all the species crashed. A few specimens came to lights on the red brick walls of the Margaret Barber Collegiate Institute. Some are pinned for future reference.

Would the larvae provide food for young birds just out of their nests? How wide spread, geographically, was the Crambus crash? If observers would watch in 2014 to see if the Crambus would return, it would be a neat bit of data.

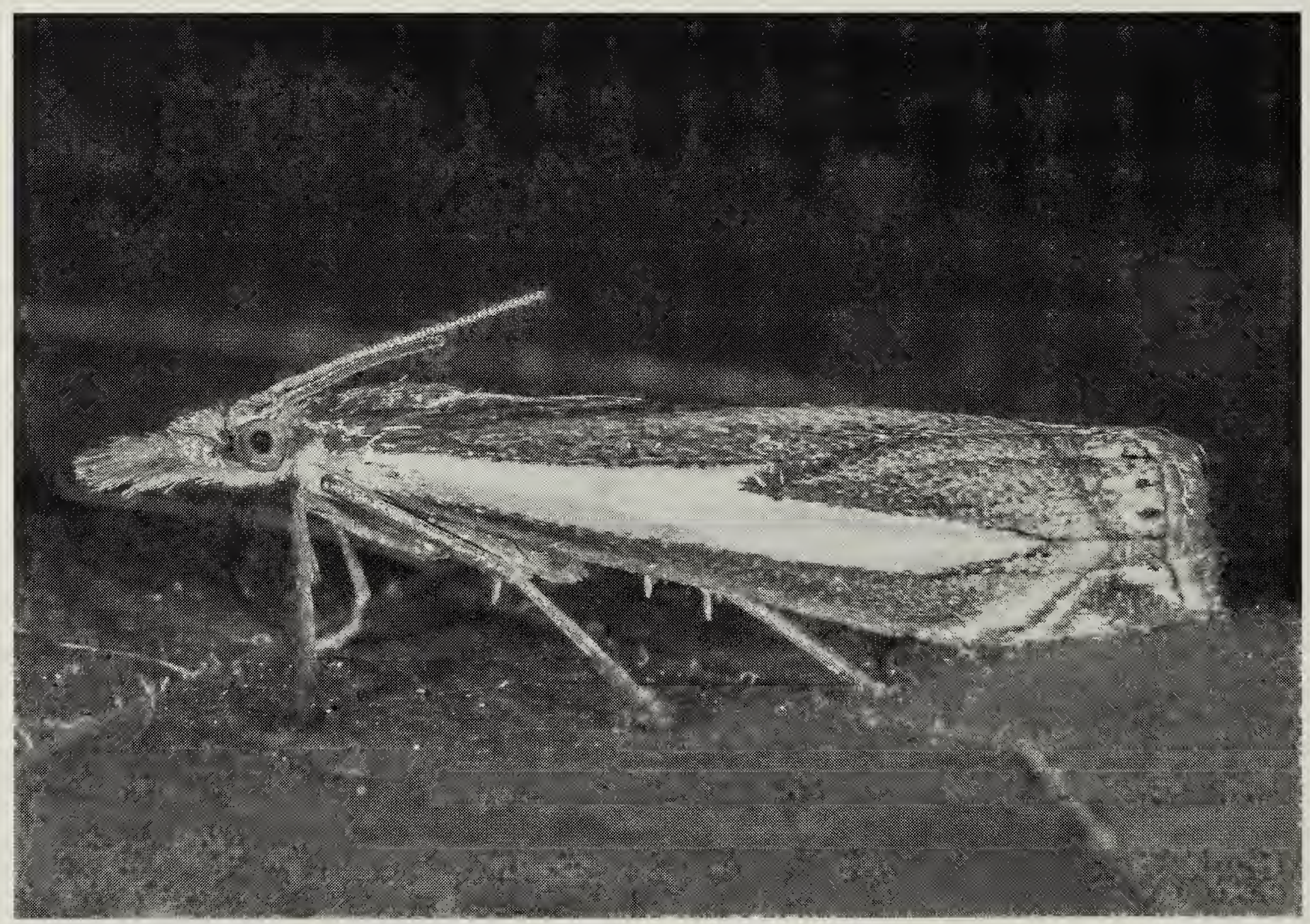

